\title{
Efeito Inibitório De Monoterpenos Frente A Klebsiella Pneumoniae Produtoras de ESBL
}

\author{
The Inhibitory Effect of Monoterpenes against ESBL-Producing \\ Klebsiella pneumoniae
}

\author{
MARIAALANA NERES DE PONTES ${ }^{1}$ \\ DIJACI SANTOS DE LIMA ${ }^{1}$ \\ SÁVIO MARCELINO GOMES ${ }^{1}$ \\ BERNADETE HELENA CAVALCANTI SANTOS ${ }^{2}$ \\ IGARA OLIVEIRA LIMA ${ }^{3}$
}

\section{RESUMO}

Introdução: Klebsiella pneumoniae é um bacilo Gram negativo membro da família Enterobacteriaceae, em que seus principais sítios de infecção se encontram no trato respiratório e urinário. Devido ao crescimento desenfreado da automedicação, vários microrganismos vem desenvolvendo mecanismos de resistência com maior frequência, desta forma tornando o tratamento cada vez difícil, sendo necessária a pesquisa de novas alternativas terapêuticas mais eficientes. Diversos produtos naturais têm sido estudados, a exemplo dos óleos essências e dos monoterpenos que vem apresentando ação bastante promissora frente aos microrganismos. Objetivo: Nessa perspectiva, este trabalho teve como objetivo avaliar a ação antibacteriana dos fitoconstituintes citral, citronelal e citronelol contra as cepas de K. pneumoniae produtora de betalactamase de amplo espectro (ESBL) e determinar a concentração inibitória mínima (CIM) destes monoterpenos. Materiais e Métodos: Foi realizada a técnica de microdiluição seriada a uma razão de dois, nas concentraç̃es de 2048, $1024,512,256,128,64$ a $32 \mu \mathrm{g} / \mathrm{mL}$, utilizando como meio de cultura o caldo Mueller Hinton, reservando a última coluna para o controle do crescimento microbiano, testando também a esterilidade do meio de cultura. Os experimentos foram realizados em triplicata e incubados na estufa a uma temperatura de 37 Cú \pm 2 Cú, por um período de 24 horas, tendo como avaliação dos ensaios o método visual. Resultados: Através dos experimentos realizados, notouse que os fitoconstituintes citral, citronelal e citronelol não inibiram o crescimento das cepas de K. pneumonia nas condições e concentrações testadas. Conclusão: Os monoterpenos não apresentaram atividade antibacteriana contras cepas testadas.

\section{DESCRITORES}

antimicrobianos; terpenos; bactérias gram-negativas.

\begin{abstract}
Introduction: Klebsiella pneumoniae is a Gram-negative bacillus of the Enterobacteriaceae family which may infect primarily the respiratory and urinary tracts. Due to the uncontrolled growth of self-medication, various microorganisms have been developing resistance mechanisms with a greater frequency, thus making infections increasingly difficult to treat. Further research is then required to develop new, more effective treatment options. Several natural products have been studied, such as essential oils and monoterpenes, which have shown promising activity against selected microorganisms. Objective: This study aimed to evaluate the antibacterial activity of the phytochemicals citral, citronellal and citronellol against $K$. pneumoniae strains producing extended-spectrum beta-lactamases (ESBL), and to determine the minimum inhibitory concentration (MIC) of these monoterpenes. Material and Methods: A serial microdilution technique was performed to test the samples at concentrations of 2048, 1024, 512, 256, 128, 64 and $32 \mathrm{ig} /$ $\mathrm{mL}$. Mueller Hinton broth was employed as the culture medium, and the last column was used for the control of microbial growth and medium sterility. The experiments were carried out in triplicate and incubated at 37 CÚ \pm 2 CÚ for 24 hours, followed by visual reading. Results: The phytochemicals citral, citronellal and citronellol did not inhibit the growth of $K$. pneumonia strains under the conditions and concentrations tested. Conclusion: The monoterpenes presented herein showed no antibacterial activity against the tested strains.
\end{abstract}

\section{DESCRIPTORS}

Antimicrobials; Terpenes; Gram-negative bacteria.

\footnotetext{
1 Alunos da graduação/ Universidade Federal de Campina Grande - UFCG/ Cuité - Paraíba;

2 Técnica de nível superior/ Universidade Federal da Paraíba - UFPB/ João Pessoa - Paraíba;

3 Professora - pesquisadora / Universidade Federal de Campina Grande - UFCG/ Cuité - Paraíba.
} 
K Tebsiella pneumoniae é um bacilo Gramnegativo, membro da família Enterobacteriaceae, que podem ser encontrados em ambientes como solo, água e plantas ${ }^{1,2}$. A referente espécie faz parte da microbiota intestinal normal e sua virulência está associada à presença de uma cápsula polissacarídica, onde se trata de um sistema de captação de ferro, fenótipo mucoide e lipopolissacarídeo tóxico ${ }^{3}$. Os locais mais comuns de infecção, são os tratos urinário e respiratório, podendo também encontrar diversas quantidades de bactérias no sangue, ou seja, bacteremia. As infecções causadas por esta espécie também estão correlacionadas com pacientes que se encontra com seu sistema imunológico debilitado, assim sendo um fator favorável no desenvolvimento de doenças ${ }^{1,2}$.

O número de surtos hospitalares causados por $K$. pneumoniae vem aumentando com a mudança no padrão de sensibilidade bacteriano sendo este influenciado pelo uso errôneo de antimicrobianos de amplo espectro e monobactâmicos, principalmente cefalosporina de terceira geração ${ }^{4}$ Um dos mecanismos de importância relevante é a produção de betalactamases, as quais são enzimas capazes de hidrolisar cefalosporinas de terceira e quarta geração, assim as transformando para sua forma inativa, destacando-se a produção de betalactamases de amplo espectro ${ }^{5,6}$.

Produtos naturais vem demonstrando uma grande eficiência no combate á infecções bacterianas, onde com isso só justifica a grande variedade de drogas oriundas desses produtos naturais que vem aumentando devido esses benefícios que os mesmos apresentam ${ }^{7}$. Nesta perspectiva, cada vez mais pesquisas vem sendo desenvolvidas com o intuito de investigar novos fármacos com ação antimicrobiana ou ainda, se possível, moléculas que modulem a atividade de antibióticos ${ }^{8,9}$.

Desta forma, pelos monoterpenos citral, citronelal e citronelol serem moléculas promissoras, se faz necessário testar a atividade antimicrobiana dos mesmos frente às cepas de K. pneumoniae produtoras de ESBL, em busca de alternativas terapêuticas que diante do surgimento de cepas multirresistentes.

Terpenos são os principais compostos de óleos essenciais das plantas aromáticas, a exemplo do citral (geranial e neral), que se trata de um monoterpeno acíclico e aldeído, onde é encontrado em diversas plantas, como Cymbopogon citratus (Capim - limão), possuindo várias atividades biológicas, dentre elas e em especial, a ação antimicrobiana. Essa ação antimicrobiana do citral foi comprovada ${ }^{10}$ frente às cepas de Staphylococcus aureus meticilina resistente, Penicillium italicum e Rhizopus stolonifer, onde utilizaram o método de difusão em ágar.

O citronelal pertence ao grupo dos álcoois monoterpenoides, sendo ele o principal componente nas misturas de compostos químicos terpenoides, assim proporcionando ao óleo de citronela um aroma bem acentuado de limão ${ }^{11}$. Além disso encontra-se como uma das substâncias majoritárias de óleos essenciais de plantas aromáticas ${ }^{12}$, como as do Gênero Cymbopogon ${ }^{13,14}$ e Eucalyptus ${ }^{13,15}$. O citronelal vem revelando ter diversas atividades, onde favorece a sua utilização na indústria, dentre elas, podemos exemplificar ação antimicrobiana ${ }^{14,16}$, alelopática $^{13,15}$, antioxidante ${ }^{17,18}$, herbicida ${ }^{13} \mathrm{e}$ atividade inseticida e repelente ${ }^{19}$.

O citronelol apresenta-se como um dos componentes do óleo essencial de algumas plantas medicinais bastante utilizadas na medicina popular, como o Cymbopogon citratus e a Lippia alba. Já foram registrados e comprovado dentre seus efeitos farmacológicos que o citronelol apresenta atividades antibacteriana, antifúngica, antiespasmódico, além de ações anticonvulsivantes ${ }^{20}$.

A partir destas premissas tem-se como objetivo determinar a concentração inibitória mínima (CIM) dos fitoconstituintes, afim de averiguar à ação destes frente a cepas bacterianas multirresistentes, uma vez que estes monoterpenos não apresentam semelhança estrutural aos medicamentos a qual a resistência é encontrada.

\section{MATERIAIS E MÉTODOS}

A presente pesquisa foi realizada no laboratório de Microbiologia (J11) no Centro de Educação e Saúde I Universidade Federal de Campina Grande.

As cepas utilizadas de $K$. pneumoniae ESBL foram: A-363, A-368, 73, 23, C-46 e LJ-09, sendo estas de origem clínica isoladas de urina e secreções orofaringe. Os meios de culturas utilizados foram caldo Brain Heart Infusion e o sólido Muller Hinton.

Os fitoconstituintes testados foram o citral, 
citronelal e o citronelol (Sigma Aldrich). Para o seu preparo utilizou-se o Tween 80 , assim auxiliando na solubilização dos monoterpenos (citral, citronelal e citronelol) para diluir em água. Todas as substâncias relatadas foram adquiridas comercialmente pela Sigma Aldrich.

$O$ inoculo foi ajustado utilizando o método visual de acordo com a escala de 0,5 Mc Farland em suspensão do microrganismo em solução salina $0,85 \%$, sendo diluído até atingir a concentração de $10^{8} \mathrm{UFC} \mathrm{mL} \mathrm{mL}^{-1}$.

A determinação da CIM dos fitoconstituintes selecionados foi realizada pela técnica da microdiluição em Placa de 96 orifícios e fundo em "U" para cada uma das cepas. Através da diluição seriada a uma razão de 2 , foram obtidas as concentrações de 1024 a $1 \mathrm{ig} / \mathrm{mL}$, efetuadas na própria placa, da coluna 1 até a 11. A última coluna (12) foi reservada para o controle de crescimento do microrganismo (caldo Brain Heart Infusion, sem o produto testado). Foi realizado o controle para observar a viabilidade da cepa (caldo e cepa) e controle de esterilidade (caldo), além da toxicidade do veículo ${ }^{21-23}$.

Em seguida, foi adicionado 10iL do inoculo (bactéria a 0,5 McFarland) em cada um dos poços. Esse ensaio foi realizado em triplicata, e em seguida as placas foram incubadas a $37^{\circ} \mathrm{C}$ no período de 24 horas para K. pneumoniae. Após o tempo de incubação adequado, usou-se $20 \mu \mathrm{L}$ resarzurina a 1\% (SIGMA, Cidade, País), que se trata de um indicador colorimétrico de óxido-redução para bactérias, onde é adicionado e a leitura foi procedida visualmente, pela ausência ou presença de crescimento do microrganismo através da observação da mudança da coloração da solução de azul para rosa/vermelho. Portanto, será determinada como CIM, a menor concentração do produto capaz de inibir o crescimento do microrganismo ensaiado, verificado por uma não mudança da coloração do corante indicador ${ }^{21-23}$.

\section{RESULTADOS E DISCUSSÃO}

Com os constantes aumentos de meios de resistência ao qual as bactérias têm apresentado, sendo a maior parte resultante da automedicação desenfreada pelos próprios pacientes, o combate à resistência microbiana acaba sendo uma grande preocupação por parte da Organização Mundial de Saúde. Com isso, para o desenvolvimento de ações de controle e prevenção da resistência é necessário que haja uma preocupação maior direcionada às áreas de educação, incluindo o uso racional de antimicrobianos, de pesquisa e de estudos de vigilância ${ }^{24}$. Dessa forma, os programas de pesquisas têm realizado descobertas que viabilizam alternativas terapêuticas secundárias, sendo o citral uma destas, já que apresentou ação antimicrobiana contra cepas de alguns fungos, como Cândida albicans e tropicalis e também contra algumas bactérias, tanto gram positivas, como o Staphylococcus aureus, como também gram negativas, a exemplo da Pseudomonas aeruginosa e da Escherichia coli, sendo essa última parte da mesma família da Klebsiella pneumoniae estudada no presente trabalho ${ }^{25}$.

A Tabela 1 ilustra os resultados referentes à ação antibacteriana do citral contra as cepas de K. pneumoniae, onde houve crescimento da bactéria em todos os níveis de concentrações aplicadas, assim não apresentando nenhuma concentração inibitória mínima (CIM) do monoterpeno estudado.

Testes sobre a atividade antimicrobiana do eucalipto citriodora (Eucalyptus cytriodora), foram realizados, a qual apresentam em grande parte de sua composição o fitoconstituinte citronelal, contra algumas bactérias e constatou atividade deste óleo essencial frente às cepas de $E$. coli e Staphylococcus $s p p^{26}$. Já em outro estudo ao qual foi realizado experimentos com o capim citronela (Cymbopogon nardus L.), que contém em sua composição, dentre outros fitoconstituintes, o citronelal, contra o fungo Fusarium subglutinans obteve-se um resultado de $100 \%$ de inibição do crescimento micelial, demonstrando assim uma alta atividade fungicida, no entanto, esse efeito pode estar relacionado ao sinergismo que ocorre devido a interação dos vários compostos presentes no óleo essencial, podendo potencializar seu efeito ${ }^{16}$.

Ambos os estudos fortaleciam a ideia de uma possível atividade antimicrobiana do citronelal contra microrganismos patogênicos, o que não se dá às cepas de $K$. pneumoniae relatadas no presente artigo, pois, como expresso na Tabela 2, os resultados da CIM do citronelal foram semelhantes de quando testado o fitoconstituinte 


\begin{tabular}{|c|c|c|c|c|c|c|}
\hline & $\begin{array}{c}\text { K. } \\
\text { pneumoniae } \\
\text { A-363 }\end{array}$ & $\begin{array}{c}\text { K. } \\
\text { pneumoniae } \\
\text { A-368 }\end{array}$ & $\begin{array}{c}K . \\
\text { pneumoniae } \\
73\end{array}$ & $\begin{array}{c}K . \\
\text { pneumoniae } \\
23\end{array}$ & $\begin{array}{c}K . \\
\text { pneumoniae } \\
C-46\end{array}$ & $\begin{array}{c}\text { K. } \\
\text { pneumoniae } \\
\text { LJ-09 }\end{array}$ \\
\hline $\begin{array}{c}2048 \\
\mu \mathrm{q} / \mathrm{ml}\end{array}$ & + & + & + & + & + & + \\
\hline $\begin{array}{c}1024 \\
\mathrm{\mu q} / \mathrm{ml}\end{array}$ & + & + & + & + & + & + \\
\hline $\begin{array}{c}512 \\
\mu \mathrm{g} / \mathrm{ml}\end{array}$ & + & + & + & + & + & + \\
\hline $\begin{array}{r}256 \\
\mu \mathrm{g} / \mathrm{ml}\end{array}$ & + & + & + & + & + & + \\
\hline $\begin{array}{c}128 \\
\mu \mathrm{gq} / \mathrm{ml}\end{array}$ & + & + & + & + & + & + \\
\hline $\begin{array}{c}64 \\
\mu \mathrm{g} / \mathrm{ml}\end{array}$ & + & + & + & + & + & + \\
\hline $\begin{array}{c}32 \\
\mu \mathrm{g} / \mathrm{ml}\end{array}$ & + & + & + & + & + & + \\
\hline
\end{tabular}

\begin{tabular}{|c|c|c|c|c|c|c|}
\hline & $\begin{array}{c}\text { K. } \\
\text { pneumoniae } \\
\text { A-363 }\end{array}$ & $\begin{array}{c}\text { K. } \\
\text { pneumoniae } \\
\text { A-368 }\end{array}$ & $\begin{array}{c}K . \\
\text { pneumoniae } \\
73\end{array}$ & $\begin{array}{c}\text { K. } \\
\text { pneumoniae } \\
23\end{array}$ & $\begin{array}{c}K . \\
\text { pneumoniae } \\
C-46\end{array}$ & $\begin{array}{c}\text { K. } \\
\text { pneumoniae } \\
\text { LJ-09 }\end{array}$ \\
\hline $\begin{array}{c}2048 \\
\mu \mathrm{g} / \mathrm{ml}\end{array}$ & + & + & + & + & + & + \\
\hline $\begin{array}{c}1024 \\
\mu \mathrm{g} / \mathrm{m} /\end{array}$ & + & + & + & + & + & + \\
\hline $\begin{array}{c}512 \\
\mu \mathrm{g} / \mathrm{ml}\end{array}$ & + & + & + & + & + & + \\
\hline $\begin{array}{c}256 \\
\mu \mathrm{g} / \mathrm{ml}\end{array}$ & + & + & + & + & + & + \\
\hline $\begin{array}{c}128 \\
\mu \mathrm{g} / \mathrm{ml}\end{array}$ & + & + & + & + & + & + \\
\hline $\begin{array}{c}64 \\
\mu \mathrm{g} / \mathrm{ml}\end{array}$ & + & + & + & + & + & + \\
\hline $\begin{array}{c}32 \\
\mu \mathrm{g} / \mathrm{ml}\end{array}$ & + & + & + & + & + & + \\
\hline
\end{tabular}

citral, não apresentando também atividade inibitória frente as cepas estudadas, em nenhuma das concentrações aplicadas.

O efeito antimicrobiano do óleo essencial de citronela (Cymbopogon winterianus Jowitt), que apresenta tanto o citronelal como o citronelol em sua composição, os resultados mostraram uma sensibilidade dos microrganismos $E$. coli e $P$. aeroginosa frente à sua atividade ${ }^{17}$. Além disso, este mesmo óleo essencial foi foco de estudos e mostrou-se possuir atividade antimicrobiana efetiva contra cepas de Escherichia coli, Staphylococcus aureus, Pseudomonas aeruginosa, Proteus vulgaris, Shigella flexneri e Bacillus cereus ${ }^{27}$.

No entanto, ao ser testado o fitoconstituinte citronelol neste estudo, observou-se o mesmo resultado dos outros monoterpenos estudados aqui, demonstrando ineficiência quanto sua atividade antimicrobiana frente a cepas de K. pneumoniae, como expressado na tabela 3.

Houve relatos sobre um maior efeito inibitório dos óleos essenciais para bactérias Gram- 


\begin{tabular}{|c|c|c|c|c|c|c|}
\hline & $\begin{array}{c}\text { K. } \\
\text { pneumoniae } \\
\text { A-363 }\end{array}$ & $\begin{array}{c}\text { K. } \\
\text { pneumoniae } \\
\text { A-368 }\end{array}$ & $\begin{array}{c}\text { K. } \\
\text { pneumoniae } \\
73\end{array}$ & $\begin{array}{c}\text { K. } \\
\text { pneumoniae } \\
23\end{array}$ & $\begin{array}{c}\text { K. } \\
\text { pneumoniae } \\
\mathrm{C}-46\end{array}$ & $\begin{array}{c}\text { K. } \\
\substack{\text { pneumoniae } \\
\text { LJ-09 }}\end{array}$ \\
\hline $\begin{array}{c}2048 \\
\mu \mathrm{q} / \mathrm{ml}\end{array}$ & + & + & + & + & + & + \\
\hline $\begin{array}{c}1024 \\
\mu \mathrm{g} / \mathrm{ml}\end{array}$ & + & + & + & + & + & + \\
\hline $\begin{array}{c}512 \\
\mu \mathrm{q} / \mathrm{ml}\end{array}$ & + & + & + & + & + & + \\
\hline $\begin{array}{c}256 \\
\mu \mathrm{q} / \mathrm{ml}\end{array}$ & + & + & + & + & + & + \\
\hline $\begin{array}{c}128 \\
\mu \mathrm{q} / \mathrm{ml}\end{array}$ & + & + & + & + & + & + \\
\hline $\begin{array}{c}64 \\
\mu \mathrm{q} / \mathrm{ml}\end{array}$ & + & + & + & + & + & + \\
\hline $\begin{array}{c}32 \\
\mu \mathrm{q} / \mathrm{ml}\end{array}$ & + & + & + & + & + & + \\
\hline
\end{tabular}

positivas em relação às Gram-negativas ${ }^{18}$. Esse mecanismo de resistência de bactérias Gram-negativas é explicado por sua riqueza de polissacarídeos na membrana externa, inibindo a penetração das substâncias antimicrobianas ${ }^{28}$.

Estudos relatam maior eficiência antimicrobiana de aldeídos, como o citral e citronelal, quando comparados a álcoois, como o citronelol ${ }^{29}$. No entanto, o sinergismo, que é o aumento da atividade de compostos quando aplicados em conjunto, se mostra como uma alternativa para potencializar a ação antimicrobiana destas substâncias, além de ser também uma forma de produzir um novo tipo de resistência medicamentosa, podendo ser viável e mais eficaz no combate a microrganismos ${ }^{30,31}$. Dessa forma, os óleos essenciais quando utilizados em associação, apresentam um maior efeito frente

\section{REFERÊNCIAS}

1. Podschun R, Ullmann R. Klebsiella spp. as Nosocomial Pathogens: Epidemiology, Taxonomy, Typing Methods, and Pathogenicity Factors. Clinical Microbiology Reviews. 1998; 11 (4): 589-603.

2. Cerqueira AS, Machado P, Marto J, Lito L, Melo-Cristino J, Duarte A. Persistência de Klebsiella pneumoniae em doentes de unidades pediátricas do Hospital de Santa Maria, em Lisboa. Acta Pediátrica. 2011; 42 (2): 49-53.

3. Pfaller AM, Jones RN, Doern GV, Kugler K. Bacterial pathogens isolated from patients with bloodstream infection: frequencies of occurrence and antimicrobial susceptibility patterns from the SENTRY antimicrobial surveillance program (United States and Canada, 1997). Antimicrob Agent Chemother. 1998; 42 (7):1762-70. aos microrganismo, assim alcançando resultados mais eficazes e bastante promissores do que quando testados de forma isolada.

\section{CONCLUSÃO}

Através dos experimentos realizados no presente estudo, notou-se que os monoterpenos citral, citronelal e citronelol não inibiram o crescimento das cepas de K. pneumoniae, assim não apresentando atividade antibacteriana contra as mesmas. Portanto, devido à importância da contribuição dos óleos essenciais e sua atividade antimicrobiana comprovada em alguns microrganismos, se faz necessário mais estudos pela busca de novas alternativas para o combate de bactérias multirresistente.

4. Scarpate ECB, Cossatis JJ. A presença da Klebsiella pneumoniae produtora de â- lactamase de espectro estendido no ambiente hospitalar. Saúde \& Ambiente. 2009; 4 (1):1-11.

5. Silva KC, Lincopan N. Epidemiologia das betalactamases de espectro estendido no Brasil: impacto clínico e implicações para o agronegócio. Jornal Brasileiro de Patologia e Medicina Laboratorial. 2012; 48 (2):91-99.

6. Gupta A, Ampofo K, Rubenstein D, Saiman L. Extended Spectrum b Lactamase-producing Klebsiella pneumoniae Infections: a Review of the Literature. Journal of Perinatology. 2003; 23 (6):439-443. 
7. Fernebro J. Fighting bacterial infections - Future treatment options. Drug Resistance Updates. 2001; 14 (2):125-139.

8. Coutinho HDM, Costa JGM, Lima EO, Falcao-Silva VS, Siqueira-Junior JP. In vitro interference of Momordica charantia and chlorpromazine in the resistance to aminoglycosides. Pharmaceutical Biology. 2008; 47 (11):1056-1059.

9. Veras HNH, Rodrigues FFG, Botelho MA, Menezes IRA, Coutinho HDM, Costa JGM. Enhancement of aminoglycosides and b-lactams antibiotic activity by essential oil of Lippia sidoides Cham. and the Thymol. Arabian Journal of Chemistry. 2013.

10. Saddiq AA, Khayyat SA. Chemical and antimicrobial studies of monoterpene: Citral. Pesticide Biochemistry and Physiology. 2010; 98 (1):89-93.

11. Kim JK, Kang CS, Lee JK, Kim YR, Han HY, Yun HK. Evaluation of Repellency Effect of Two Natural Aroma Mosquito Repellent Compunds Citronella and Citronellal. Entomological Research. 2005; 35 (2):117-120.

12. Quintans-Júnior L, Rocha RFD, Caregnato FF, Moreira JCF, Silva FAD, Araújo AADS, Gelain DP. Antinociceptive action and redox properties of citronelal, an essential oil present in lemon grass. Journal of Medicinal Food. 2011; 14 (6):630-639.

13. Brito DR, Ootani MA, Ramos ACC, Sertão WC, Souza ARW. Efeito dos óleos de citronela, eucalipto e composto citronelal sobre micoflora e desenvolvimento de plantas de milho. Journal of Biotechnology and Biodiversity. 2012; 3 (4):184-192.

14. Cavalcanti YM, Almeida LFD, Padilha WWN. Screening of essential oils antifungal activity on Candida strains. Odontologia Clínica-Científica. 2011; 11 (3):243-246.

15. Tomaz MA, Costa AV, Rodrigues WN, Pinheiro PF, Parreira LA, Rinaldo D, et al. Chemical Composition and Allelopathic Activity of the Eucalyptus Essential Oil. Bioscience Journal, Uberlândia. 2014; 30 (5):475-483.

16. Seixas TL, Castro HC, Santos GR, Cardoso DP. Controle fitopatológico do Fusarium subglutinans pelo óleo essencial do capim-citronela (Cymbopogon nardus L.) e do composto citronelal. Revista Brasileira de Plantas Medicinais, Botucatu. 2011; 13 (Especial):523-526.

17. Scherer R, Wagner R, Duarte MCT, Godoy HT. Composição e atividades antioxidante e antimicrobiana dos óleos essenciais de cravo-da-índia, citronela e palmarosa. Rev Bras Plantas Med. 2009; 11 (4):442449.

18. Andrade MA, das Graças Cardoso M, Batista LR, Mallet ACT, Machado SMF. Óleos essenciais de Cymbopogon nardus, Cinnamomum zeylanicum e Zingiber officinale: composição, atividades antioxidante e antibacteriana. Revista Ciência Agronômica. 2012; 43 (2):399-408.

19. de Souza, Chagas AC, Passos WM, Prates HT, Leite RC, Furlong J, Fortes ICP. Efeito acaricida de óleos essenciais e concentrados emulsionáveis de Eucalyptus spp em Boophilus microplus. Brazilian Journal of Veterinary Research and Animal Science. 2002; 39 (5):247-253.

20. Bastos JF, Moreira ÍJ, Ribeiro TP, Medeiros IA, Antoniolli AR, De Sousa DP, Santos MR. Hypotensive and vasorelaxant effects of citronellol, a monoterpene alcohol, in rats. Basic \& Clinical Pharmacology \& Toxicology. 2009; 106(4):331-337.
21. CLSI M7-A6. Metodologia dos Testes de Sensibilidade a Agentes Antimicrobianos para Bactérias de Crescimento Aeróbio: Norma Aprovada - Sexta Edição. Vol. 23. 2005.

22. Sarker SD, Nahar L, Kumarasamy Y. Microtitre platebased antibacterial assay incorporating resazurin as an indicator of cell growth, and its application in the in vitro antibacterial screening of phytochemicals. Methods. 2007; 42 (4):321-324.

23. Hussain Al, Anwar F, Nigam PS, Sarker SD, Moore JE. Antibacterial activity of some Lamiaceae essential oils using resazurin as na indicator of cell growth. Food Science and Technology. 2011; 44 (4):1199-1206.

24. Wollheim C. Epidemiologia molecular de Escherichia coli e Klebsiella spp. Produtoras de beta-lactamases de espectro ampliado. Dissertação de mestrado. Universidade de Caxias do Sul; Programa de PósGraduação em Biotecnologia, 2009.

25. Santos A, Paduan RH, Gazin ZC, Jacomassi E, D'oliveira OS, Cortez DAG, Cortez LER. Determinação do rendimento e atividade antimicrobiana do óleo essencial de Cymbopogoncitratus(DC.) Stapf em função de sazonalidade e consorciamento. Brazilian Journal of Pharmacognosy. 2009; 19 (2):436-441.

26. Estanislau AA, Barros FAS, Peña AP, Santos SC, Ferri $\mathrm{PH}$, Paula JR. Composição química e atividade antibacteriana dos óleos essenciais de cinco espécies de Eucalyptus cultivadas em Goiás. Rev Bras Farmacogn. 2001; 11 (2): 95-100.

27. Gonçalves TB, Sousa EOD, Rodrigues FF, Costa JGMD. Chemical composition and antibacterial evaluation of the essential oil from Cymbopogon winterianus Jowitt (Gramineae). Journal of Essential Oil Bearing Plants. 2010; 13 (4): 426-431.

28. BURT, S. Essential oils: their antibacterial properties and potential applications in foods-a review. International journal of food microbiology. 2004; 94 (3): 223-253.

29. Kalemba D, Kunicka A. Antibacterial and antifungal properties of essential oils. Current Medicinal Chemistry. 2003; 10 (10): 813-829.

30. Williamson EM. Synergy and other interactions in phytomedicines. Phytomedicine. 2001; 8 (5): 401-409.

31. Ceylan E, Fung DYC. Antimicrobial activity of spices. Journal of Rapid Methods and Automation in Microbiology. 2004; 12 (1): 1-55.

\section{Correspondência}

Maria Alana Neres de Pontes

Rua Jair Lourenço $N^{\circ} 53$

Centro / Santa Cruz - RN

CEP 59200-000

mariaalanapontes@gmail.com 